\title{
Genetic parameter estimation of 16-month live weight and objectively measured wool traits in the Tygerhoek Merino flock
}

\author{
P.A. Matebesi ${ }^{1,2}$, S.W.P. Cloete ${ }^{3,4 \#}$ and J.B. van Wyk ${ }^{2}$ \\ ${ }^{1}$ Department of Animal Sciences, National University of Lesotho, P.O. Roma 180, Lesotho \\ ${ }^{2}$ Department of Animal, Wildlife and Grassland Sciences, University of the Free State, P.O. Box 339, \\ Bloemfontein 9300, South Africa \\ ${ }^{3}$ Department of Animal Sciences, Stellenbosch University, Private Bag X1, Matieland 7602, South Africa \\ ${ }^{4}$ Institute for Animal Production: Elsenburg, Private Bag X1, Elsenburg 7607, South Africa
}

\begin{abstract}
Genetic evaluation systems require the accurate estimation of genetic parameters. The genetic, phenotypic and environmental parameters for live weight and objectively measured wool traits were estimated for a South African Merino flock. Records of the Tygerhoek Merino resource flock were used to estimate these parameters. The database consisted of records of 4495 animals, the progeny of 449 sires and 1831 dams born in the period 1989 to 2004 . The pedigree records used have been collected between 1969 and 2004. Direct heritability estimates $\left(\mathrm{h}^{2}{ }_{\mathrm{a}}\right)$ for 16-month live weight (LW) and objectively measured wool traits ranged from 0.20 for staple strength (SS) to 0.68 for fibre diameter (FD). Maternal heritability estimates ranged from 0.05 for $\mathrm{LW}$ and FD, to 0.10 for clean fleece weight (CFW). The proportion of the total phenotypic variance due to the maternal permanent environment variance $\left(\mathrm{c}^{2}{ }_{\mathrm{pe}}\right)$ amounted to $5 \%$ for fleece weights. The genetic correlation between animal effects for LW, greasy fleece weight (GFW) and CFW were $-0.28,-0.65$ and -0.70 respectively. The genetic correlation between LW and CFW was positive, but low at 0.14 . The other important genetic correlations among the wool traits ranged from low to high, and were variable in sign ((for GFW with CFW (0.87) and with staple length (SL - 0.18); CFW with clean yield (CY - 0.33) and with SL (0.29); FD with CY (-0.09), with SL (0.15), with SS (0.40) and with standard deviation of FD (SDFD - 0.38): CY with SL (0.33) and with SDFD (0.10); SS with coefficient of variation of FD (CVFD - -0.57) and with SDFD (-0.28); CVFD with SDFD (0.87)). These results suggested that worthwhile responses in the objectively measured traits can be achieved through direct and indirect selection.
\end{abstract}

Keywords: Direct heritability, maternal effects, correlations, 16-months body and fleece weight, fibre traits, staple traits

${ }^{\#}$ Corresponding author. Email: schalkc@elsenburg.com

\section{Introduction}

Objectively measured wool traits and body weight remain the most economically important traits in a wool enterprise, apart from reproduction (Olivier, 1999). The genetic improvement of these traits is important for increased productivity and profitability. Knowledge of variance components and the accurate estimation of the genetic parameters are required to design breeding programmes for the genetic improvement of these traits.

Sophisticated computer software has been developed to derive accurate estimates of genetic parameters (Meyer, 1991; Gilmour et al., 1999). These software packages enable the partitioning of genetic variances into direct additive and maternal additive effects, the covariance between animal effects, animal permanent environmental effect as well as the maternal permanent environmental effects (Lewis \& Beatson, 1999). The advent of these software packages enabled researchers to partition the respective random effects for various livestock species and breeds (Meyer, 1992; 1994; Olivier et al., 1994; Purvis, 1995; Swan et al., 1995; Snyman et al., 1995; 1996; Meyer, 1997). In addition, Van Wyk et al. (2003) and Safari et al. (2007b) partitioned the dam environmental variance into a temporary litter effect and a permanent environmental effect (the correspondence of records of the same dam across breeding seasons) to accurately reflect the contribution of the respective components. Furthermore, Asadi Fozi et al. (2005) reported the importance of including maternal genetic effects for fleece traits in Merino breeding programmes. 
A successful genetic improvement plan for economically important performance traits in woolled sheep depends on a well-defined selection objective and a thorough understanding of the correlated responses in other traits because of the selection objective. Genetic parameters for ovine production traits have been studied widely in the past and were reviewed by Fogarty (1995), Snyman et al. (1995) and Safari et al. (2005) for a wide range of traits recorded on woolled sheep, dual-purpose sheep and meat sheep. Moreover, the genetic and phenotypic correlations among objective wool traits and body weight have been estimated for many South African Merino populations (Snyman et al., 1995; Cloete et al., 1998; Olivier et al., 2006; Van Wyk et al., 2008). However, few studies included staple strength (SS), coefficient of variation of fibre diameter (CVFD), and the standard deviation of fibre diameter (SDFD) in the analyses. No local publications involving these traits could be sourced. There is also little information about genetic, phenotypic and environmental correlations among objective wool and body weight traits of economic importance. Maternal correlations among objective wool and body weight traits were absent in the literature cited. Against this background the present study estimated the (co)variance components as well as the genetic, phenotypic, environmental and maternal correlations for 16-months live weight and objectively measured wool traits in a South African Merino flock.

\section{Materials and Methods}

The experimental flock is maintained on the Tygerhoek experimental farm, near Riviersonderend in the Western Cape Province of South Africa. The experimental site is situated at latitude $33^{\circ} 30^{\prime}$ south and longitude $21^{\circ} 11^{\prime}$ east. The climate at the site is Mediterranean, with $60 \%$ of the average total precipitation of $426 \mathrm{~mm}$ being recorded between April and September. The climate at the site is mild with cool winters (average maximum temperatures of $17.8-18.7{ }^{\circ} \mathrm{C}$ and average minimum temperatures of $5.0-6.0{ }^{\circ} \mathrm{C}$ recorded between June and August) and mild summers (average maximum temperatures of $27.7-28.8^{\circ} \mathrm{C}$ and average minimum temperatures of $14.3-15.8^{\circ} \mathrm{C}$ recorded between December and January).

The origin and initial selection in the flock were first described by Heydenrych (1975) and Heydenrych et al. (1984). Subsequent analyses on animals from the flock involved studies on reproduction (Cloete, 1986) and early live weight as well as testicular size and reproduction (Duguma, 2002). Data utilized in the present study were collected from 1989 and 2004 and consisted of records of 4495 animals, the progeny of 449 sires and 1831 dams. The pedigree records that were used have been collected between 1969 and 2004. The selection lines involved were the following:

o Fine wool: Individuals of this line are descendents of a line similar to that maintained at Cradock (Olivier et al., 1999; 2006), from where ewes were introduced to Tygerhoek in 1997. During the formation of the Cradock flock, ewes were screened from their original flocks on the basis of a low fibre diameter and above average live weight

o Fleece weight: This line was selected since 1970 for an increase in clean fleece weight with a check on fibre diameter (Cloete et al., 1998).

o Wet and dry: Ewes in this line have been culled since 1993 on failure to lamb or to rear at least one lamb per lambing opportunity. During this period, rams were selected as described by Cloete \& Scholtz (1998). This line was discontinued in 2002.

o Control: This line was maintained as a control, no directed selection was applied since 1970, although it was shown that this line was not genetically stable for all traits (Cloete et al., 1998).

Traits included in the analyses were live weight (LW - defined as the weight measured at 16 months of age after shearing, without fasting), greasy fleece weight (GFW), clean fleece weight (CFW), clean yield (CY), fibre diameter (FD), staple length (SL) and staple strength (SS). Two measurements of the variability of FD were also included in the analysis, namely standard deviation of FD (SDFD) and the coefficient of variation of FD (CVFD). Greasy fleece weight was recorded at shearing in August-September each year, while the measures of wool quality were determined on a midrib wool sample taken from each animal at 14 - 16 months of age. Information on GFW was combined with CFW data to derive CY.

The statistical analysis was divided into three consecutive steps. Firstly, the significance of fixed effects was tested using the ASREML programme (Gilmour et al., 2002) leaving only significant effects in the final model. The fixed effects included in the model were sex (male or female), type of birth (singles or multiples), age of dam ( 2 to $6^{+}$years), year of birth (1989 - 2004), selection line (1 to 4 ) and the sex by year interaction (1 to 32$)$. 
The second step was the estimation of (co)variance components for each trait using the ASREML programme (Gilmour et al., 2002), fitting single-trait animal models initially. These models include a combination of direct additive, maternal additive and maternal permanent environmental effects as well as the covariation between direct and maternal additive effects, resulting in the following models (in matrix notation):

$\begin{array}{ll}\text { Model 1 } & \mathrm{Y}=\mathrm{X} \beta+\mathrm{Z}_{1} \mathrm{a}+\mathrm{e} \\ \text { Model 2 } & \mathrm{Y}=\mathrm{X} \beta+\mathrm{Z}_{1} \mathrm{a}+\mathrm{Z}_{2} \mathrm{~m}+\mathrm{e}\{\text { with } \operatorname{cov}(\mathrm{a}, \mathrm{m})=0\} \\ \text { Model 3 } & \mathrm{Y}=\mathrm{X} \beta+\mathrm{Z}_{1} \mathrm{a}+\mathrm{Z}_{2} \mathrm{~m}+\mathrm{e}\left\{\text { with } \operatorname{cov}(\mathrm{a}, \mathrm{m})=\mathrm{A} \sigma_{\mathrm{am}}\right\} \\ \text { Model 4 } & \mathrm{Y}=\mathrm{X} \beta+\mathrm{Z}_{1} \mathrm{a}+\mathrm{Z}_{2} \mathrm{~m}+\mathrm{Z}_{3} \mathrm{c}+\mathrm{e}\{\text { with } \operatorname{cov}(\mathrm{a}, \mathrm{m})=0\} \\ \text { Model 5 } & \mathrm{Y}=\mathrm{X} \beta+\mathrm{Z}_{1} \mathrm{a}+\mathrm{Z}_{2} \mathrm{~m}+\mathrm{Z}_{3} \mathrm{c}+\mathrm{e}\left\{\text { with } \operatorname{cov}(\mathrm{a}, \mathrm{m})=\mathrm{A} \sigma_{\mathrm{am}}\right\} \\ \text { Model 6 } & \mathrm{Y}=\mathrm{X} \beta+\mathrm{Z}_{1} \mathrm{a}+\mathrm{Z}_{3} \mathrm{c}+\mathrm{e}\end{array}$

In these models, $\mathrm{y}$ was a vector of observations for different traits, $\beta, \mathrm{a}, \mathrm{m}$ and $\mathrm{c}$ were vectors of fixed effects influencing traits, direct additive effects, random maternal additive (dam) effects, random permanent maternal environmental effects and e was a randomly distributed vector of residuals. $X, Z_{1}, Z_{2}$ and $Z_{3}$ are considered as the corresponding incidence matrices relating observations to the respective fixed and random effects as well as the vector of residuals. The variance-covariance structure of the effects was:

$\operatorname{var}\left(\begin{array}{l}\mathrm{a} \\ \mathrm{m} \\ \mathrm{c} \\ \mathrm{e}\end{array}\right)=\left(\begin{array}{llll}\mathrm{A} \sigma_{\mathrm{a}}^{2} & \mathrm{~A} \sigma_{\mathrm{am}} & 0 & 0 \\ \mathrm{~A} \sigma_{\mathrm{am}} & \mathrm{A} \sigma_{\mathrm{m}}^{2} & 0 & 0 \\ 0 & 0 & \mathrm{INd \sigma ^{2 }} & 0 \\ 0 & 0 & 0 & \mathrm{IN \sigma _{ \textrm {e } } ^ { 2 }}\end{array}\right)$

With $\mathbf{A}$ being the numerator relationship matrix among animals in the pedigree file, $\mathbf{I}$ is an identity matrix, $\mathbf{N d}$ represents the number of dams and $\mathbf{N}$ is the number of records. The (co) variances $\sigma_{\mathrm{a}}^{2}, \sigma_{\mathrm{m}}^{2}, \sigma_{\mathrm{am}}, \sigma_{\mathrm{c}}^{2}$ and $\sigma_{\mathrm{e}}^{2}$ were defined as the direct genetic variance, the maternal genetic variance, the covariance between the direct and maternal genetic effects, the permanent environmental variance due to the dam and the residual (error) variance, respectively. The phenotypic variance $\left(\sigma_{\mathrm{p}}^{2}\right)$ was defined as the sum of all variance components estimated in the model of analysis, and could be derived from all the above-mentioned variances, as appropriate for the specific analysis. Heritability estimates were computed as the direct heritability $\left(\mathrm{h}_{\mathrm{a}}^{2}=\sigma_{\mathrm{a}}^{2} / \sigma_{\mathrm{p}}^{2}\right)$ and the maternal heritability $\left(\mathrm{h}_{\mathrm{m}}^{2}=\sigma_{\mathrm{m}}^{2} / \sigma_{\mathrm{p}}^{2}\right)$.

The significance of the random effects was tested using the log likelihood ratio tests after inclusion of one random effect in the model. A random effect was considered significant when its inclusion in the model caused a significant improvement in the log likelihood ratio. A chi-square distribution of $\alpha=0.05$ at one degree of freedom was used as a test statistic (3.841). When -2 times the difference between the $\log$ likelihoods was greater than this critical value, the inclusion of the particular random effect was considered to significantly improve the fit of the model (Swalve, 1993). The objective of testing the significance of different models is to identify the best and simplest models that could be used for subsequent runs. Therefore the model with the least possible number of random effects was used when the inclusion of an additional random effect was not significant. The third and final step was to estimate genetic, environmental, phenotypic and maternal correlations among all traits by fitting two-trait models using ASREML (Gilmour et al., 2002). Starting values for the (co)variance components of two-trait models were obtained from the single trait models fitted in step two.

\section{Results}

Descriptive statistics for live weight and objective wool traits are presented in Table 1. Preliminary analysis of non genetic effects indicated that birth status (single/multiple), sex (male/female), age of the dam in years $\left(2-6^{+}\right.$years $)$, year of birth $(1989-2004)$ selection line $(1-4)$ and the sex*birth year interaction had 
significant $(\mathrm{P}<0.05)$ effects on all objective wool traits and live weight and were included in the models for subsequent analyses. Live weight was highly variable with a coefficient of variation (CV) of 19.79\%, while CV's for the objectively measured wool traits ranged from $7.94 \%$ to $36.39 \%$ with SS being the most variable trait (Table 1). The qualitative wool traits, CY and FD showed less variation than the other objective wool traits $(<10 \%)$.

Table 1 Descriptive statistics for the raw data pertaining to live weight and objective wool traits for Tygerhoek Merino sheep

\begin{tabular}{lcccccc}
\hline Trait & $\mathrm{n}$ & Mean & SD & CV (\%) & Min & Max \\
\hline Live weight $(\mathrm{kg})$ & 4993 & 49.5 & 9.8 & 19.79 & 18.5 & 93.5 \\
Greasy fleece weight $(\mathrm{kg})$ & 4824 & 5.1 & 1.29 & 25.29 & 1.0 & 9.4 \\
Clean fleece weight $(\mathrm{kg})$ & 4816 & 3.6 & 0.95 & 26.24 & 0.7 & 7.0 \\
Clean yield $(\%)$ & 4890 & 71.8 & 5.70 & 7.94 & 49.9 & 84.1 \\
Staple length $(\mathrm{mm})$ & 4618 & 89.7 & 16.60 & 18.51 & 33.0 & 144.1 \\
Staple strength $(\mathrm{N} / \mathrm{ktex})$ & 1914 & 34.9 & 12.70 & 36.39 & 2.0 & 74.0 \\
Fibre diameter $(\mu \mathrm{m})$ & 4890 & 19.9 & 1.70 & 8.54 & 14.4 & 27.6 \\
CV of fibre diameter $(\%)$ & 4047 & 20.2 & 2.70 & 13.37 & 13.7 & 39.0 \\
SD of fibre diameter $(\mu \mathrm{m})$ & 4047 & 4.0 & 0.60 & 15.00 & 2.1 & 6.8
\end{tabular}

$\mathrm{n}$ - number of observations; SD - standard deviation; CV - coefficient of variation; Min - minimum; Max - maximum; $\mathrm{CV}$ of fibre diameter - coefficient of variation of fibre diameter; SD of fibre diameter - standard deviation of fibre diameter.

Table 2 Log likelihood ratios for the respective random effects models fitted for live weight and wool traits for Tygerhoek Merino sheep with the "best" model in bold

\begin{tabular}{lcccccc}
\hline Traits & Model 1 & Model 2 & Model 3 & Model 4 & Model 5 & Model 6 \\
\hline LW & -11069.0 & -11060.9 & $\mathbf{- 1 1 0 5 9 . 0}$ & -11060.8 & -11058.9 & -11064.3 \\
GFW & -1455.15 & -1447.08 & -1437.18 & -1443.10 & $\mathbf{- 1 4 3 3 . 7 8}$ & -1443.43 \\
CFW & -189.557 & -181.649 & -168.824 & -178.737 & $\mathbf{- 1 6 5 . 9 0 5}$ & -179.234 \\
CY & $\mathbf{- 8 7 3 8 . 0 8}$ & -8738.02 & -8737.72 & -8738.05 & -8737.72 & -8738.08 \\
SL & $\mathbf{- 1 2 3 8 1 . 7}$ & -12381.8 & N/C & -12381.7 & N/C & -12381.7 \\
SS & $\mathbf{- 5 5 4 5 . 0 2}$ & -5544.05 & -5543.75 & -5544.31 & -5543.75 & -5544.81 \\
FD & -3427.76 & -3423.62 & $-\mathbf{3 4 1 9 . 9 7}$ & -3423.62 & -3419.88 & -3424.17 \\
CVFD & $\mathbf{- 4 4 4 6 . 3 6}$ & -4446.07 & -4445.65 & -4446.14 & -4445.66 & -4446.36 \\
SDFD & $\mathbf{7 5 0 . 3 7 2}$ & 750.369 & N/C & 750.371 & N/C & 750.371
\end{tabular}

LW - live weight; GFW - greasy fleece weight; CFW - clean fleece weight; CY - clean yield; SL - staple length; SS - staple strength; FD - fibre diameter; CVFD - coefficient of variation of fibre diameter; SDFD - standard deviation of fibre diameter; N/C - analysis failed to converge.

The most appropriate single-trait animal model for GFW and CFW was Model 5 (Table 2) which included the direct additive and maternal additive effects, the covariance between animal effects as well as 
the dam permanent environmental effect, while Model 3 that included direct and maternal additive effects as well as their covariance was most appropriate for FD and LW (Table 2). The model with only the additive effect (Model 1) fitted the data best for CY, SL, SS, CVFD and SDFD (Table 2).

Direct single-trait heritability estimates $\left(\mathrm{h}_{\mathrm{a}}^{2}\right)$ for objective wool traits (Table 3 ) ranged between 0.20 for staple strength to 0.68 for fibre diameter. Live weight was moderately heritable at 0.38 (Table 3). Estimates of maternal heritability $\left(\mathrm{h}^{2}\right)$ amounted to 0.05 for LW, 0.10 for CFW, 0.09 for GFW and 0.05 for FD. The dam permanent environmental component $\left(\mathrm{c}^{2}{ }_{\mathrm{pe}}\right)$ accounted for $5 \%$ of total phenotypic variance for fleece weights (both CFW and GFW). The genetic correlations between animal effects were negative and amounted to -0.28 for $\mathrm{LW},-0.65$ for GFW, -0.70 for CFW and -0.43 for FD. Heritability estimates derived from the two-trait analyses were consistent with the single-trait estimates, and are therefore not presented.

Table 3 Direct and maternal additive effects, the covariance between animal effects, and the maternal permanent environmental effect for Tygerhoek Merino sheep, as derived from single-trait analyses

\begin{tabular}{lcccc}
\hline \multicolumn{1}{c}{ Trait } & $\mathrm{h}_{\mathrm{a}}^{2} \pm$ s.e. & $\mathrm{h}_{\mathrm{m}}^{2} \pm$ s.e. & $\mathrm{c}_{\mathrm{pe}}^{2}$ & $\sigma_{\mathrm{am}}$ \\
\hline Live weight $(\mathrm{kg})$ & $0.38 \pm 0.05$ & $0.05 \pm 0.02$ & & $-0.28 \pm 0.12$ \\
Greasy fleece weight $(\mathrm{kg})$ & $0.36 \pm 0.05$ & $0.09 \pm 0.03$ & $0.05 \pm 0.02$ & $-0.65 \pm 0.10$ \\
Clean fleece weight $(\mathrm{kg})$ & $0.40 \pm 0.05$ & $0.10 \pm 0.03$ & $0.05 \pm 0.02$ & $-0.70 \pm 0.09$ \\
Clean yield (\%) & $0.65 \pm 0.03$ & - & - & - \\
Staple length (mm) & $0.37 \pm 0.03$ & - & - & - \\
Staple strength (N/ktex) & $0.20 \pm 0.05$ & - & - & - \\
Fibre diameter $(\mu \mathrm{m})$ & $0.68 \pm 0.05$ & $0.05 \pm 0.02$ & - & - \\
CV of fibre diameter (\%) & $0.61 \pm 0.04$ & - & - & - \\
SD of fibre diameter (\%) & $0.61 \pm 0.03$ & - & - & \\
\end{tabular}

$\mathrm{h}_{\mathrm{a}}^{2}$ - direct heritability; $\mathrm{h}_{\mathrm{m}}^{2}$ - maternal heritability; $\sigma_{\mathrm{am}}$ - covariance between animal effects;

$\mathrm{c}_{\mathrm{pe}}^{2}$ - dam permanent environmental effect; s.e. - standard error.

Many of the genetic correlations among LW and wool traits (Table 4) were not significant and thus of limited economic importance. The significant correlations were between LW and CFW (0.14 \pm 0.07$)$, for GFW with CFW $(0.87 \pm 0.02)$ and with SL $(0.18 \pm 0.06)$, for CFW with CY $(0.33 \pm 0.05)$ and with SL $(0.29$ $\pm 0.06)$, for FD with CY $(-0.09 \pm 0.04)$, with SL $(0.15 \pm 0.05)$, with SS $(0.40 \pm 0.09)$ and with SDFD $(0.38$ $\pm 0.05)$, for CY with SL $(0.33 \pm 0.05)$ and with SDFD $(0.10 \pm 0.05)$, for SS with CVFD $(-0.57 \pm 0.09)$ and with SDFD $(-0.28 \pm 0.10)$ and of CVFD with SDFD $(0.87 \pm 0.01)$. Phenotypic correlations among these traits were low $(-0.05$ between FD and CY) to high ( 0.89 between GFW and CFW) in magnitude and variable in sign (Table 4) with only three correlations which were not significant (between CVFD and the wool weights, and between SS and SDFD). Environmental correlations were also low to high and ranged from 0.12 to 0.91 . Maternal correlations for LW with GFW and CFW were $0.84 \pm 0.12$ and $0.46 \pm 0.12$ respectively. Corresponding correlations for GFW with CFW $(0.86 \pm 0.05)$ and FD $(0.08 \pm 0.02)$ were positive. CFW and FD were also positively related at $0.19 \pm 02$ on the maternal level.

\section{Discussion}

High variation has been reported for live weight and quantitative wool traits (GFW, CFW, and SL) among Merinos and other sheep breeds. Coefficient of variation (CV) for LW ranged from $6.0 \%$ to $28.0 \%$ (Brown et al., 2005; Safari et al., 2005; Miraei-Ashtiani et al., 2007; Olivier \& Cloete, 2007; Safari et al., 
Table 4 Genetic (above diagonal) and phenotypic (below diagonal) correlations among live weight and objective wool traits

\begin{tabular}{|c|c|c|c|c|c|c|c|c|c|}
\hline Traits & LW & GFW & $\mathrm{CFW}$ & FD & $\mathrm{CY}$ & $\mathrm{SL}$ & $\mathrm{SS}$ & CVFD & SDFD \\
\hline LW & & $0.13 \pm 0.07$ & $0.14 \pm 0.07^{*}$ & $-0.01 \pm 0.06$ & $0.08 \pm 0.06$ & $0.05 \pm 0.12$ & $0.09 \pm 0.07$ & $-0.15 \pm 0.07$ & $-0.13 \pm 0.06$ \\
\hline GFW & $0.37 \pm 0.01 *$ & & $0.87 \pm 0.02 *$ & $0.08 \pm 0.06$ & $-0.09 \pm 0.05$ & $0.18 \pm 0.06$ & $-0.07 \pm 0.11$ & $0.04 \pm 0.06$ & $0.11 \pm 0.06$ \\
\hline CFW & $0.36 \pm 0.02 *$ & $0.89 \pm 0.00 *$ & & $0.04 \pm 0.06$ & $0.33 \pm 0.05 *$ & $0.29 \pm 0.06^{*}$ & $-0.12 \pm 0.11$ & $0.02 \pm 0.06$ & $0.08 \pm 0.06$ \\
\hline FD & $0.14 \pm 0.02 *$ & $0.21 \pm 0.02 *$ & $0.18 \pm 0.02 *$ & & $-0.09 \pm 0.04 *$ & $0.15 \pm 0.05^{*}$ & $0.40 \pm 0.09 *$ & $-0.08 \pm 0.05$ & $0.38 \pm 0.05^{*}$ \\
\hline $\mathrm{CY}$ & $0.06 \pm 0.02 *$ & $-0.06 \pm 0.02 *$ & $0.23 \pm 0.02 *$ & $-0.05 \pm 0.02 *$ & & $0.33 \pm 0.05^{*}$ & $0.01 \pm 0.10$ & $-0.04 \pm 0.05$ & $-0.10 \pm 0.05$ \\
\hline SL & $0.10 \pm 0.02 *$ & $0.26 \pm 0.02 *$ & $0.30 \pm 0.02 *$ & $0.19 \pm 0.02 *$ & $0.22 \pm 0.02 *$ & & $0.19 \pm 0.12$ & $-0.11 \pm 0.07$ & $-0.03 \pm 0.07$ \\
\hline SS & $0.16 \pm 0.02 *$ & $0.10 \pm 0.02 *$ & $0.10 \pm 0.02 *$ & $0.29 \pm 0.02 *$ & $0.08 \pm 0.03 *$ & $0.14 \pm 0.03 *$ & & $-0.57 \pm 0.09 *$ & $-0.28 \pm 0.10 *$ \\
\hline CVFD & $-0.16 \pm 0.02 *$ & $0.02 \pm 0.02$ & $-0.01 \pm 0.02$ & $-0.10 \pm 0.02 *$ & $-0.12 \pm 0.02 *$ & $0.14 \pm 0.02 *$ & $-0.39 \pm 0.02$ & & $0.87 \pm 0.01 *$ \\
\hline SDFD & $-0.06 \pm 0.02 *$ & $0.15 \pm 0.02 *$ & $0.10 \pm 0.02 *$ & $0.38 \pm 0.02 *$ & $-0.13 \pm 0.02 *$ & $-0.02 \pm 0.02$ & $0.21 \pm 0.02 *$ & $0.86 \pm 0.01^{*}$ & \\
\hline
\end{tabular}

* - significant correlations; LW - live weight; GFW - greasy fleece weight; CFW - clean fleece weight; CY - clean yield; SL - staple length; SS - staple strength; FD - fibre diameter; CVFD - coefficient of variation of fibre diameter; SDFD - standard deviation of fibre diameter.

Table 5 Environmental (above diagonal) and maternal (below diagonal, where applicable) correlations among live weight and objective wool traits

\begin{tabular}{|c|c|c|c|c|c|c|c|c|c|}
\hline Traits & LW & GFW & CFW & FD & $\mathrm{CY}$ & $\mathrm{SL}$ & SS & CVFD & SDFD \\
\hline LW & & $0.48 \pm 0.02 *$ & $0.48 \pm 0.03 *$ & $0.31 \pm 0.04 *$ & $0.06 \pm 0.04$ & $0.12 \pm 0.04 *$ & $0.22 \pm 0.03 *$ & $-0.18 \pm 0.05 *$ & $-0.01 \pm 0.04$ \\
\hline GFW & $0.84 \pm 0.12 *$ & & $0.91 \pm 0.01 *$ & $0.39 \pm 0.04 *$ & $-0.06 \pm 0.04$ & $0.33 \pm 0.03 *$ & $0.18 \pm 0.04^{*}$ & $0.01 \pm 0.04$ & $0.21 \pm 0.04 *$ \\
\hline CFW & $0.46 \pm 0.12 *$ & $0.86 \pm 0.05^{*}$ & & $0.36 \pm 0.04 *$ & $0.18 \pm 0.04^{*}$ & $0.34 \pm 0.03 *$ & $0.21 \pm 0.04 *$ & $-0.05 \pm 0.04$ & $0.13 \pm 0.04 *$ \\
\hline FD & $0.16 \pm 0.17$ & $0.08 \pm 0.02 *$ & $0.19 \pm 0.02 *$ & & $0.02 \pm 0.05$ & $0.25 \pm 0.04^{*}$ & $0.28 \pm 0.05^{*}$ & $-0.15 \pm 0.06^{*}$ & $0.42 \pm 0.05^{*}$ \\
\hline $\mathrm{CY}$ & - & - & - & - & & $0.12 \pm 0.04 *$ & $0.14 \pm 0.05^{*}$ & $-0.25 \pm 0.05^{*}$ & $-0.19 \pm 0.05^{*}$ \\
\hline SL & - & - & - & - & - & & $0.12 \pm 0.04 *$ & $-0.18 \pm 0.05^{*}$ & $0.02 \pm 0.04$ \\
\hline SS & - & - & - & - & - & - & & $-0.35 \pm 0.05^{*}$ & $-0.19 \pm 0.05^{*}$ \\
\hline CVFD & - & - & - & - & - & - & - & & $0.85 \pm 0.02 *$ \\
\hline
\end{tabular}

* - significant correlations.

See Table 4 for abbreviations. 
2007a; Van Wyk et al., 2008). Corresponding values for GFW, CFW and SL ranged from $16.2 \%$ to $28.3 \%$ (Brown et al., 2005; Safari et al., 2005; Hanford et al., 2006; Safari et al., 2007a), from $16.2 \%$ to $42.0 \%$ (Safari et al., 2005; Olivier \& Cloete, 2007; Safari et al., 2007a; Van Wyk et al., 2008;) and from 11.9 to 20.9 (Naidoo et al., 2004; Safari et al., 2005; Notter et al., 2007) respectively. Coefficients of variation for LW and quantitative wool traits in the present study were also high and ranged from $18.5 \%$ for SL to $26.2 \%$ for CFW. Staple strength showed high variation at $36.4 \%$ in the current study which is higher than the range (19.3\% to $29.0 \%$ ) obtained in the literature (Naidoo et al., 2004; Safari et al., 2005; Notter et al., 2007).

The qualitative wool traits FD and CY showed less variation $(<10 \%)$ in the current study. This is in agreement with other literature values (Brown et al., 2005; Safari et al., 2005; Van Wyk et al., 2008; Safari et al., 2007a; Olivier \& Cloete, 2007), with an exception of a higher CV of 11.97\% for FD reported by Safari et al. (2007a) in Australian Merino resource flocks. The two measures of variation in FD (CVFD and SDFD) showed variations of $13.4 \%$ and $15.0 \%$, respectively. The current values are within the literature ranges of $12.2 \%$ to $16.6 \%$ for CVFD, and $13.1 \%$ to $18.1 \%$ for SDFD (Safari et al., 2005; Notter et al., 2007; Safari et al., 2007a).

Several studies reported significant maternal effects for LW, GFW and CFW for various sheep breeds (Asadi Fozi et al., 2005; Cloete et al., 2005; Safari et al., 2005). In contrast, Vaez Torshizi et al. (1996) reported no significant maternal effects for any of the corresponding objective wool traits beyond 12 months of age. In a study involving Australian resource flocks, Safari et al. (2007b) found a significant maternal additive effect, the covariance between animal effects, animal permanent environmental effect as well as a litter effect at 14 - 17-months of age for LW, GFW, CFW, FD, CY, SD and CV. The results from the current study and literature strongly indicate that more random effects should be considered during the estimation of models for 16-months LW and some objectively assessed wool traits.

Literature estimates of the direct heritability $\mathrm{h}_{\mathrm{a}}^{2}$ for 16-months live weight ranged from $0.13-0.55$ (Safari et al., 2005; Brown et al., 2005; Van Wyk et al., 2008). Corresponding estimates of $\mathrm{h}_{\mathrm{m}}{ }_{\mathrm{m}}$ ranged from 0.01 to 0.09 . The present estimates are within the range of these values. Weighted mean estimates of $h^{2}{ }_{a}$ were 0.38 for GFW and 0.36 for CFW derived from literature values for wool breeds (Safari et al., 2005) and $\mathrm{h}_{\mathrm{m}}^{2}$ were 0.08 and 0.06 , respectively. The present estimates are in agreement with values derived from literature values by Safari et al. (2005), and somewhat lower than the values (0.46 and 0.42, 0.08 and 0.07) reported for Australian Merino resource flocks (Safari et al., 2007b). The current $\mathrm{h}^{2}$ a estimate for CFW is also lower than the recent estimate of $\mathrm{h}^{2}$ of 0.54 (Olivier et al., 2006) for CFW involving Merino sheep and higher than that of 0.17 reported for the South African Dohne Merino breed (Van Wyk et al., 2008).

Estimated weighted mean $\mathrm{h}^{2}$ a for wool breeds were 0.56 for CY and 0.46 for SL (Safari et al., 2005). The current estimates of respectively 0.65 and 0.37 are broadly consistent with those published estimates. In contrast, Safari et al. (2007b) reported a lower value for CY of 0.47 when the covariance between animal effects was included as an additional random effect in the model and 0.42 when the covariance between animal effects was excluded. Furthermore, Olivier \& Cloete (2007) reported a lower $\mathrm{h}^{2}$ estimate of 0.26 in South African Merino sheep participating in the Merino Plan compared to the present estimate of 0.37. The former lower estimate was attributed to possible wool growth period differences in sheep of the national flock, which may be as short as six months, leading to an overcorrection when corrected to a growth period of a year. Safari et al. (2005) derived weighted mean $\mathrm{h}^{2}$ estimates of 0.57 for FD and 0.52 for CVFD. The current $\mathrm{h}^{2}{ }_{\mathrm{a}}$ estimates are somewhat higher than these values. Oliver et al. (2006) also reported a lower $\mathrm{h}^{2}{ }_{\mathrm{a}}$ of 0.63 for FD for the Cradock fine wool flock. Current $\mathrm{h}^{2}$ a estimate of 0.20 for SS is lower than the weighted mean value of 0.34 derived for wool breeds in general (Safari et al., 2005) and that of 0.23 (broad wool stud) to 0.48 (fine wool stud) estimated for South African Merino sheep by Herselman et al. (2006). Standard deviation of fibre diameter was highly heritable at 0.61 . This estimate is consistent with other literature values that ranged from 0.49 to 0.60 (Safari et al., 2005; Notter et al., 2007; Safari et al., 2007b).

The dam permanent environmental effect $\left(\mathrm{c}^{2}{ }_{\mathrm{pe}}\right)$ accounted for $5 \%$ of the total phenotypic variance for the fleece weights. None of the literature sources cited reported significant $\mathrm{c}_{\mathrm{pe}}^{2}$ effects for fleece weights. Correlations between animal effects for GFW, CFW and FD were high and negative in the current study. This is in agreement with the values reported for Australian Merinos (Asadi Fozi et al., 2005; Safari et al., 2007b). The correlation between animal effects for LW estimated in the present study was moderate in magnitude and negative in sign (-0.28). In contrast, Safari et al. (2007b) reported a moderate and positive 
correlation of 0.25 between animal effects for LW. The weighted mean value reported by Safari et al. (2005) using four estimates was positive and very high in magnitude $(0.74)$ compared to the present value.

Favourable genetic correlations existed between LW and CFW (0.14), for GFW with CFW (0.87) and with SL (0.18), for CFW with CY (0.33) and with SL (0.29), for FD with CY (-0.09), for CY with SL (0.33), for SS with CVFD (-0.57) and with SDFD (-0.28) and for CVFD with SDFD (0.87). These relationships accord well with those reported by Safari et al. (2005) from literature values for corresponding traits as well as with those reported by Olivier \& Cloete (2007) between CFW and SL, and between LW and CFW. Unfavourable relationships occurred for FD with SL (0.15), SS (0.40) and SDFD (0.38). Similar results were reported in the literature (Safari et al., 2005). Unfavourable relationships also occurred between FD and SL in a South African Merino breed analysis (Olivier \& Cloete, 2007).

The most striking aspect of the present results is a non-significant genetic correlation of $0.04 \pm 0.06$ between CFW and FD. A previous study by Erasmus et al. (1990) reported a similar non-significant genetic correlation of $0.06 \pm 0.16$ between CFW and FD. On the contrary, Safari et al. (2005) derived a higher mean genetic correlation of 0.28 from the literature values. Recent South African studies also reported higher genetic correlations that ranged from 0.14 to 0.20 (Olivier et al., 2006; Olivier \& Cloete, 2007; Van Wyk et al., 2008) for the genetic correlation between CFW and FD. These differences may be attributed to the inclusion of the maternal genetic correlation in the two-trait analysis between CFW and FD in the current study. A greater portion of the genetic correlation between CFW and FD may have been partitioned to the maternal genetic covariance, as indicated by the somewhat higher maternal correlation of 0.19 . Although the genetic correlation between CFW and FD was not significant, the relationship between fleece weights and FD were positive in the bulk of supporting literature. However, it needs to be stated that maternal correlations were not considered in most studies. Phenotypic and environmental correlations between LW and objective wool traits were comparable in direction and ranged from low to high. Maternal correlations were 0.84 between LW and GFW, 0.46 between LW and CFW, 0.85 between fleece weights, 0.08 between GFW and FD and 0.19 between CFW and FD. The maternal correlation was accordingly high $(0.98)$ between GFW and CFW in Australian Merinos (Asadi Fozi et al., 2005).

\section{Conclusions}

The results from the study generally corresponded with the most recent literature parameter estimates for live weight and objective wool traits. These results also emphasise the importance of the model of choice to be used in the analysis of live weight and objective wool traits in South African Merino sheep. Moderate to high heritability estimates suggest responses to selection, and the feasibility of genetic change in live weight, wool weight and wool quality. It is also evident that antagonistic relationships between animal effects are unlikely to compromise responses to selection for LW, GFW, CFW as well as FD. This contention is supported by substantial genetic progress in the desired direction for South African Merinos (Olivier \& Cloete, 2007) and Dohne Merinos (Swanepoel, 2006) when directed selection was applied to these traits of economic importance.

The genetic correlation between the two most important determinants of the wool price (SS and FD) was moderate and unfavourable. This result has implications for selection programmes for a decreased FD, if SS needs to be maintained. Staple strength and CVFD were favourably correlated, while a favourable but low correlation was also estimated between FD and CVFD. These results suggested a favourable correlated response to selection for decreased FD when direct selection is practiced on CVFD as an indicator trait for SS (Greeff et al., 1995). Since the determination of SS is relatively expensive in South Africa, indirect selection using CVFD seems to be an option. The generally unfavourable correlations between quantitative wool traits (GFW and CFW) with some qualitative wool traits (SS, FD and CVFD) need to be considered carefully during selection for an increased profit. Fortunately the magnitude of these correlations is generally small and they are not expected to preclude progress in the overall selection objective. The genetic correlations of LW with the objective wool traits were mostly not significant, thus the correlated response to selection for these traits will either be not important or alternatively favourable, as for CVFD and SDFD.

\section{Acknowledgements}

The dedicated technical assistance of $\mathrm{E}$. du Toit and the Tygerhoek farmhands is gratefully acknowledged. Funding for this study was provided by the Kellogg foundation. 


\section{References}

Asadi Fozi, M., Van der Werf, J.H.J. \& Swan, A.A., 2005. The importance of accounting for maternal genetic effects in Australian fine-wool Merino breeding. Aust. J. Agric. Res. 56, 789-796.

Brown, D.J., Atkins, K. \& Huisman, A.E., 2005. Expression of body weight, fleece weight and fibre diameter in across flock genetic evaluation. Proc. Assoc. Advmt. Anim. Breed. Gen. 16, 481-491.

Cloete, S.W.P., 1986. A study of phenotypic and genetic aspects of reproduction in the Tygerhoek Merino flock. M.Sc. thesis, University of Stellenbosch, Stellenbosch, South Africa.

Cloete, S.W.P. \& Scholtz, A.J., 1998. Lamb survival in relation to lambing and neonatal behaviour in medium wool Merino lines divergently selected for multiple rearing ability. Aust. J. Exp. Agric. 38, 801-811.

Cloete, S.W.P., Olivier, J.J., Snyman, M.A. \& Du Toit, E., 1998. Genetic parameters and trends in a selection experiment for increased clean fleece weight involving South African Merinos. Aust. J. Exp. Agric. 38, 427-432.

Cloete, S.W.P., Olivier, J.J., Van Wyk, J.B., Schoeman, S.J. \& Erasmus, G.J., 2005. Genetic parameters and trends for hogget traits in Merino lines divergently selected for multiple rearing ability. Proc. Assoc. Advmt. Anim. Breed. Genet. 16, 24-27.

Duguma, G., 2002. A genetic study of early growth traits and ewe productivity in Merino sheep. M.Sc. thesis, University of Stellenbosch, Stellenbosch, South Africa.

Erasmus, G.J., De Lange, A.O., Delport, G.J. \& Olivier, J.J., 1990. Genetic and phenotypic parameter estimates of production traits of Merino sheep in an arid environment. S. Afr. J. Anim. Sci. 20, 31-34.

Fogarty, N.M., 1995. Genetic parameters for live weight, fat and muscle measurements, wool production and reproduction in sheep: a review. Anim. Breed. Abstr. 63, 101-143.

Gilmour, A.R., Cullis, B.R., Welham, S.J. \& Thompson, R., 1999. ASREML-Reference manual. NSW Agriculture Biometric Bulletin No.3. NSW Agriculture, Orange Agricultural Institute, Forest Road, Orange 2800, NSW, Australia.

Gilmour, A.R., Gogel, B.J., Cullis, B.R., Welham, S.J. \& Thompson, R., 2002. ASREML-User Guide Release 1.0 VSN International Ltd, Hemel Hempstead, HPI IES, UK.

Greeff, J.C., Lewer, R.P., Ponzoni, R.W. \& Purvis, I.W., 1995. Staple strength: progress towards elucidating its place in Merino breeding. Proc. Aust. Assoc. Anim. Breed. Gen. 11, 595-601.

Hanford, K.J., Van Vleck, L.D. \& Snowder, G.D., 2006. Estimates of genetic parameters and genetic trends for reproduction, weight and wool characteristics of Polypay sheep. Livest. Prod. Sci. 102, 72-82.

Herselman, M.J., Olivier, J.J. \& Snyman, M.A., 2006. Determining the relationship between staple strength and production and subjectively assessed wool traits. Proc. $41^{\text {st }}$ S. Afr. Soc. Anim. Sci. 3-6 April 2006, Bloemfontein, South Africa. Page 95.

Heydenrych, H.J., 1975. 'n Studie van kuddestatistieke, nie-genetiese faktore, genetiese parameters, en seleksievordering met betrekking tot die Tygerhoek Merinokudde. Ph.D. proefskrif, Universiteit van Stellenbosch, Stellenbosch, Suid-Afrika.

Heydenrych, H.J., Du Plessis, J.J. \& Cloete, S.W.P., 1984. Increasing the wool production of Merino sheep in South Western Districts of South Africa by direct and indirect selection. Proc. $2^{\text {nd }}$ Wrld Congr. Sheep Beef Cattle Breed., 16-19 April 1984, Pretoria. Eds Hofmeyr, J.H. \& Meyer, E.H.H., South African Stud Book and Livestock Improvement Association, Bloemfonten (1984), 399-412.

Lewis, R.M. \& Beatson, P.R., 1999. Choosing maternal-effect models to estimate (co) variance for live and fleece weight in New Zealand Coopworth sheep. Livest. Prod. Sci. 58, 137-150.

Meyer, K., 1991. 'DFREML: Programs to Estimate Variance components by Restricted Maximum Likelihood using a Derivative-free Algorithm.' User notes, Version 2.0.

Meyer, K., 1992. Variance components due to direct and maternal effects on growth traits in Australian beef cattle. Livest. Prod. Sci. 31, 178-204.

Meyer, K., 1994. Estimates of direct and maternal effects on growth traits in Australian beef cattle. Livest. Prod. Sci. 38, 91-105.

Meyer, K., 1997. Estimates of genetic parameters for weaning weight of beef accounting for direct-maternal environmental covariances. Livest. Prod. Sci. 52, 187-199. 
Miraei-Ashtiane, S.R., Seyedalian, S.A.R. \& Shahrbabak, M.M., 2007. Variance components and heritabilities for body weight traits in Sangsari sheep using univariate and multivariate animal models. Small Rumin. Res. 73, 108-114.

Naidoo, P., Cloete, S.W.P. \& Olivier, J.J., 2004. Heritability estimates and correlations between subjectively assessed and objectively measured fleece traits in Merino sheep. S. Afr. J. Anim. Sci. 34 (SASAS congress 2004), 38-40.

Notter, D.R., Kuehn, L.A. \& Kott, R.W., 2007. Genetic analysis of fibre characteristics in adult Targhee ewes and their relationship to breeding value estimates derived from yearling fleeces. Small Rumin. Res. 67, 164-172.

Olivier, J.J., 1999. The South African Merino performance testing scheme. In: 'Rising to the challenge Breeding for the $21^{\text {st }}$ Century Customer'. Beef Industry and CRC for Premium Quality Wool Industry Symposia. Supplement to the Proc. Assoc. Advmt Anim. Breed. Gen. 13, 119-124.

Olivier, J.J. \& Cloete, S.W.P., 2007. Genetic change in South African Merino studs participating in the Merino Plan. Proc. Assoc. Advmt. Anim. Breed. Gen. 17, 324-327.

Olivier, J.J., Bezuidenhout, A.G., Greyling, A.C. \& Cloete, S.W.P., 1999. Evaluation of genetic fine and strong $\mathrm{x}$ fine wool Merinos on irrigated pastures. Proc. Assoc. Advmt. Anim. Breed. Gen. 13, 62-65.

Olivier, J.J., Erasmus, G.J., Van Wyk, J.B. \& Konstantinov, K.V., 1994. Direct and maternal variance component estimates for clean fleece weight, body weight and mean fibre diameter in the Grootfontein Merino Stud. S. Afr. J. Anim. Sci. 24, 122-124.

Olivier, W.J., Olivier, J.J., Cloete S.W.P. \& Van Wyk, J.B., 2006. Genetic analysis of the Cradock fine wool Merino stud. Proc. $8^{\text {th }}$ Wrld Congr. Gen. Appl. Livest. Prod. 599-602.

Purvis, I.W., 1995. Strategies for improving wool quality and productivity in fine and superfine woolled Merino flocks. Proc. Aust. Assoc. Anim. Breed. Genet. 11, 510-515.

Safari, E., Fogarty, N.M. \& Gilmour, A.R., 2005. A review of genetic parameter estimates for wool, growth, meat and reproduction traits in sheep. Livest. Prod. Sci. 92, 271-289.

Safari, E., Fogarty, N.M., Gilmour, A.R., Atkins, K.D., Mortimer, S.I., Swan, A.A., Brien, F.D., Greeff, J.C. \& Van der Werf, J.H.J., 2007a. Across population genetic parameters for wool, growth, and reproduction traits in Australian Merino sheep. 1. Data structure and non-genetic effects. Aust. J. Agric. Res. 58, 169-175.

Safari, E., Fogarty, N.M., Gilmour, A.R., Atkins, K.D., Mortimer, S.I., Swan, A.A., Brien, F.D., Greeff, J.C. \& Van der Werf, J.H.J., 2007b. Across population genetic parameters for wool, growth, and reproduction traits in Australian Merino sheep. 2. Estimates of heritability and variance components. Aust. J. Agric. Res. 58, 177-184.

Snyman, M.A., Erasmus, G.J., Van Wyk, J.B. \& Olivier, J.J., 1995. Direct and maternal (co)variance components and heritability estimates for body weight at different ages and fleece traits in Afrino Sheep. Livest. Prod. Sci. 44, 229-235.

Snyman, M.A., Olivier, J.J. \& Olivier, W.J., 1996. Variance components and genetic parameters for body weight and fleece traits of Merino sheep in an arid environment. S. Afr. J. Anim. Sci. 26, 11-14.

Swalve, H.H., 1993. Estimation of direct and maternal (co)variance components for growth traits in Australian Simmental beef cattle. J. Anim. Breed. Genet. 110, 241-252.

Swan, A.A., Lax, J. \& Purvis, I.W., 1995. Genetic variation in objectively measured wool traits in CSIRO's fine wool flock. Proc. Aust. Assoc. Anim. Breed. Gen. 11, 516-520.

Swanepoel, J.W., 2006. A genetic evaluation of the Dohne Merino breed in South Africa. M.Sc. thesis, University of the Free State, Bloemfontein, South Africa.

Vaez Torshizi, R., Nicholas, F.W. \& Raadsma, H.W., 1996. REML estimates of variance and covariance components for production traits in Australian Merino sheep, using an animal model. 1. Body weight from birth to 22 months. Aust. J. Agric. Res. 47, 1235-1249.

Van Wyk, J.B., Fair, M.D. \& Cloete, S.W.P., 2003. Revised models and genetic parameter estimates for production and reproduction traits in the Elsenburg Dormer sheep stud. S. Afr. J. Anim. Sci. 33, 213-222.

Van Wyk, J.B., Swanepoel, J.W., Delport, G.J., Cloete, S.W.P., Olivier, J.J. \& Delport, G.J., 2008. Across flock genetic parameters for yearling body weight and fleece traits in the South African Dohne Merino population. S. Afr. J. Anim. Sci. 38, 31-37. 